\title{
Evaluation of Transition Barriers to Circular Economy: A Case from the Tourism Industry
}

\author{
Kemal Vatansever \\ Department of Management and Business Administration, \\ Alanya Alaaddin Keykubat University, Antalya, Turkey. \\ Corresponding author: kemal.vatansever@alanya.edu.tr

\section{Haris Akarsu} \\ Department of Management and Business Administration, \\ Alanya Alaaddin Keykubat University, Antalya, Turkey. \\ E-mail: haris.akarsu@alanya.edu.tr \\ Yiğit Kazançoğlu \\ Department of Logistics Management, \\ Yasar University, Izmir, Turkey. \\ E-mail: yigit.kazancoglu@yasar.edu.tr \\ (Received on February 21, 2021; Accepted on April 28, 2021)
}

\begin{abstract}
Current economic system exhibits a linear path by using resources to produce goods and disposing of waste after their consumption. Circular economy (CE) turns this linear pattern into a circular one by using waste as a resource for another process. It focuses on environmental responsibility, efficiency, renewable resources, preventing wastage, and, minimizing consumption. CE helps the sustainability of the economy by restructuring the production processes to use fewer resources and extending the lifetime of the products. Although there are powerful drivers for transition to CE firms often face significant barriers while implementing their plans. This study aims to evaluate the barriers that the tourism industry would face during the transition process and put them in order according to their importance. We used the Interval Type-2 Fuzzy Analytical Hierarchy Process (FAHP) method which is based on a pairwise comparison of relevant criteria to calculate the weights of importance of these barriers. We conducted semi-structured interviews with four experts from the tourism industry. According to our results, the most important barrier is organizational structure/infrastructure that creates inconvenience with the supply chain. The results are expected to be a guide for the firms in the tourism industry for their transition to CE applications.
\end{abstract}

Keywords- Circular economy, Interval type-2 fuzzy AHP, Sustainable tourism, Barriers to circular economy.

\section{Introduction}

The world has been facing a paradigm shift from linear economy (LE) to circular economy (CE) in recent years (Vargas-Sanchez, 2018). Conventional industrial economy shows a linear pattern that consists of take-make-dispose steps. In this linear model, the resources are used to produce goods which are sold to the consumers; however, these products become waste and get discarded when the consumers do not need them anymore (The Ellen MacArthur Foundation, 2013). When a product's waste is used as a resource for another product, the economy can be defined as a CE since this step transforms the linear system into a loop or circular system (Andersen, 2007). CE is a system that restores and regenerates resources by promoting renewable energy, decreasing the use of hazardous chemicals, and designing products and manufacturing systems that eliminate waste (The Ellen MacArthur Foundation, 2013). The basis of CE can be expressed as the 3R (reduce reuse - recycle) principle, which refers to reducing the amount of materials in the production 
International Journal of Mathematical, Engineering and Management Sciences

Vol. 6, No. 3, 824-846, 2021

https://doi.org/10.33889/IJMEMS.2021.6.3.049

process, reusing the products for an extended time by repairing or fixing, and, recycling the components of the products when they reach the end of their economic lives (Jiang and Zhou, 2012).

Scholars argue that CE encourages reducing the use of resources, limits the amount of waste production, and carries a potential for economic prosperity (Zink and Geyer, 2017). CE has important drivers like "government support", "company culture", "consumer demand", "social recognition", "economic attractiveness", and "information to practitioners" (Gue et al., 2020). However, transition from LE to CE is not an effortless process for companies. On the contrary, the companies must face and overcome a wide range of barriers and challenges in their transition processes. The barriers to CE can be grouped as "outsourcing barriers", "technology barriers", "knowledge barriers", "financial barriers", "involvement and support barriers" (Govindan et al., 2014) or "government-related barriers", "economic barriers", "technological barriers", "knowledge and skill related barriers", "management-related barriers", "CE framework related barriers", "cultural \& social barriers", and "market-related barriers" (Govindan and Hasanagic, 2018).

The tourism industry faces difficulties in this transition process like other industries that have to overcome the obstacles and take advantage of $\mathrm{CE}$ applications' potential gains to prosper in the new era (Vargas-Sanchez, 2018). The industry is a fast-growing industry, and it has close links with the consumption of resources and the generation of waste (Pamfilie et al., 2018). Although it creates value and helps countries develop their economies, it also damages the environment and produces high amounts of waste and pollution (Girard and Nocca, 2017). Creating new processes according to $\mathrm{CE}$, which reduces resource extraction and creates value from waste, is one of the most important principles for establishing a sustainable tourism environment (Pan et al., 2018).

This paper aims to evaluate the barriers that the tourism industry would face during the transition process from LE to CE and put these barriers in an order according to their weights determined by the evaluation of relevant literature and expert opinions. Even though the numbers of research about the barriers to CE transition have been increasing in recent years, tourism-specific research on the topic has not reached a satisfactory level yet. The existing research papers mainly offer a literature review and do not have case studies or applications. The number of researches that compare and rank the barriers to $\mathrm{CE}$ in a hierarchy is also extremely limited. Therefore, the study also aims to fill these gaps in the literature. Following the publication of the results of the study, the companies will have an opportunity to allocate their resources and efforts with respect to the weights of importance of these barriers. The weights were calculated by using the Interval Type- 2 Fuzzy Analytical Hierarchy Process method. This method is based on a pairwise comparison of relevant criteria. The following parts of the study include a detailed literature review on CE, an introduction of the methodology used, the application, and the results and discussion parts.

\section{Literature Review}

The current LE model, which exhibits a one-way take-make-dispose system, was born with the industrial revolution that did not take the overuse of resources and its long-term effects into consideration (Prieto-Sandoval et al., 2018). The growing world population, increasing purchasing power, and tendency to consume cause higher demand on the limited resources (Andrews, 2015). The combination of the increasing demand and one-way path of the LE model creates a substantial challenge on establishing sustainable development throughout the world according to many scholars (Andrews, 2015; Korhonen et al., 2018). CE framework was born as an alternative to oneway LE model, and it promotes reexamining the current relationship of humanity with the resources 
International Journal of Mathematical, Engineering and Management Sciences

Vol. 6, No. 3, 824-846, 2021

https://doi.org/10.33889/IJMEMS.2021.6.3.049

and waste to support the efficient use of resources and prevent the loss of value (Blomsma and Tennant, 2020). CE is encouraged by the European Union (EU), numerous private companies, and various governments like China, Japan, Canada, France, Sweden, Finland, and, The Netherlands (Korhonen et al., 2018).

It has been increasing the popularity of $\mathrm{CE}$ as a study subject in the last decade; however, there is no commonly accepted definition for the concept. One of the most universally accepted definitions of CE is presented by Ellen MacArthur Foundation:

"The circular economy refers to an industrial economy that is restorative by intention; aims to rely on renewable energy; minimizes, tracks, and eliminates the use of toxic chemicals; and eradicates waste through careful design" (The Ellen MacArthur Foundation, 2013).

CE is defined by Wu et al. (2014) as a system that targets to reach the optimum production level by minimizing the use of natural resources and pollution at the same time and minimizing wastage by encouraging reusing, recycling, and restoration of the waste. An analysis of 114 definitions in the literature was conducted by Kirchherr et al. (2017), and the study shows that CE is predominantly defined by the activities of reducing, reusing, and recycling while the scholars usually forget to mention the need for a systemic transition. CE concepts are mentioned alongside other environment-related concepts like sustainable development, green economy, or ecological economy from time to time. The study of Schoggl et al. (2020) affirms a subset relationship between $\mathrm{CE}$ and sustainable development, which was broadly advocated in the previous research. Arguing that the line between the $\mathrm{CE}$ and sustainability concepts is not drawn clearly in the academic or industrial literature, Geissdoerfer et al. (2017) aimed to distinguish the similarities, differences, and the relationship between these two popular concepts by reviewing the existing literature and conducting bibliometric analysis.

Various scholars link different concepts with the CE framework. Ezzat (2016) specified the concepts related with the CE model as "greening the economy", "natural capitalism", "fundamental economy", "lifecycle thinking", "creating shared value principle", "resource and energy efficiency gap", and "ecological transition" in his comparative work. Geisendorf and Pietrulla (2018) also listed the concepts related with CE model as "cradle-to-cradle", "blue economy", "regenerative design", "closed supply chains", "natural capitalism", "industrial ecology", "performance economy", "biomimicry", and "reverse logistics" in the study that they conducted to reach an updated CE definition by analyzing and comparing the existing literature. According to their observation, $\mathrm{CE}$ is mainly related to the "cradle-to-cradle" concept and even though all of the abovementioned concepts are interconnected, they differ in their main focuses, aims, and characteristics (Geisendorf and Pietrulla, 2018). Korhonen et al. (2018) listed these concepts with the help of a detailed review on the existing literature as "industrial ecology", "industrial ecosystems", "industrial symbiosis", "cleaner production", "circular material flows", "productservice systems", "eco-efficiency", "cradle-to-cradle", "biomimicry", "resilience of socialecological systems", "performance economy", "natural capitalism", and "zero emissions". Morseletto (2020) examined the importance of two other concepts, "restoration", and "regeneration" in his study. He argues that restoration can be accepted as an essential concept for $\mathrm{CE}$ applications, while regeneration might be ignored as an essential principle due to its lack of applicability. 
International Journal of Mathematical, Engineering and Management Sciences

Vol. 6, No. 3, 824-846, 2021

https://doi.org/10.33889/IJMEMS.2021.6.3.049

Producing goods with easier disassembling processes, improving the reverse cycle, leasing certain products instead of selling, and clearing landfills from organic food waste represent some possible $\mathrm{CE}$ solutions that add value to our environment and economy. These $\mathrm{CE}$ solutions provide various benefits and advantages to economies, companies, and consumers. CE implementation helps economies by saving materials, reducing price volatility, creating new employment opportunities by shifting industries, decreasing externalities, and building a more robust economic environment. The companies may benefit from the CE practices in reducing material costs and risks, enhancing customer interaction, improving customer loyalty, reducing the complexity of the goods, and, managing their lifecycles more efficiently. The consumers would have smaller ownership costs for the products; they would have more options and secondary benefits while purchasing a new product with the widespread implementation of $\mathrm{CE}$ practices in manufacturing processes (The Ellen MacArthur Foundation, 2013).

CE model proposes a significant contribution to the sustainability of the planet; however, there are certain limitations for applying the CE practices. According to Korhonen et al. (2018), the limitations can be categorized under six main groups, namely "thermodynamic limits", "system boundary limits", "limits posed by the physical scale of the economy", "limits posed by pathdependency and lock-in", "limits of governance and management", and "limits of social and cultural definitions". Moreau et al. (2017) argue that recycling strategies of CE model are weak in the aspects of having an exhaustive understanding of biophysical limitations and involvement of social and institutional participants and these weaknesses prevent handling the productivity of material and energy in the economic system.

Barriers to the implementation of CE practices is another important topic in the CE literature. Govindan et al. (2014) grouped barriers to CE implementation as "outsourcing barriers", "technology barriers", "knowledge barriers", "financial barriers", and "involvement and support barriers" and then rank them according to their importance. Ritzen and Sandstrom (2017) classified the barriers for moving towards CE under 5 main groups as "financial", "structural", "operational", "attitudinal", and "technological" barriers while Galvao et al. (2018) specified 7 barriers as "technological", "policy and regulatory", "financial and economic", "managerial", "performance indicators", "customer", and "social" barriers. Farooque et al. (2019) listed the barriers to CE as "lack of financial resources", "limited expertise, technology and information", "organizational culture and management", "uncertainty about benefits", "lack of economies of scale", "weak environmental regulations and enforcement", "lack of market preference or pressure", and "lack of collaboration/support from supply chain actors". Govindan and Hasanagic (2018) conducted a comprehensive study about the barriers that slow down the transition from LE to CE and listed 39 individual barriers under 8 clusters such as "governmental issues", "economic issues", "technological issues", "knowledge and skill issues", "management issues", "CE framework issues", "culture and social issues", and finally "market issues". They evaluated these barriers according to their relevance with internal or external environment and also their link with consumers, government, society, and organizations (Govindan and Hasanagic, 2018). Kirchherr et al. (2018) covered the same topic by conducting a survey with 208 participants and interviewing with 47 experts, and they listed 15 individual barriers under 4 main groups, namely "cultural", "market", "regulatory", and "technological" barriers. According to the results of their study, the most constraining barriers to the implementation of CE practices are cultural barriers, specifically "lacking consumer interest and awareness" and "hesitant company culture" (Kirchherr et al., 2018). According to de Jesus and Mendonca (2018), technical, economic, financial, and market barriers 
International Journal of Mathematical, Engineering and Management Sciences

Vol. 6, No. 3, 824-846, 2021

https://doi.org/10.33889/IJMEMS.2021.6.3.049

can be defined as "hard barriers" while institutional, regulatory, social, and cultural barriers can be defined as "soft barriers".

Rizos et al. (2016) conducted a research in order to understand the barriers and enablers for a CE transition for small and medium-sized enterprises (SME) in Europe. According to the results of this research, the most mentioned barriers by the SMEs were "lack of support supply and demand network", "lack of capital", "lack of government support", "administrative burden", "lack of technical know-how", "lack of information", and "company environmental culture", respectively. In comparison, the most mentioned enablers were "company environmental culture", "networking", "support from the demand network", "being financially attractive", "recognition", "personal knowledge", and "government support", again, respectively.

Goyal et al. (2018) examined the CE practices in India in the aspects of reduce, recycle, and reuse concepts in their research which was conducted to understand the implementation of CE business model in developing countries,. According to the results of their study, the main challenges on CE implementation can be categorized under four main groups; "infrastructure-level barriers and challenges" like the inefficiency of recycling processes, incompatible infrastructure, lack of industry-level abilities; "technology barriers and challenges" like lack of awareness about technologies for collection, dissociation, and extraction of metals from wastes; "ineffective policy and social barriers and challenges" like lack of social perception and government focus on the industry; "traditional approaches for processing of e-waste in developing countries" which cause severe environmental and health-related problems (Goyal et al., 2018).

Transition from a LE to a circular one is a complex process and requires a comprehensive redesign of the existing system (Vargas-Sanchez, 2018). Therefore, it must be supported by the dedication of all stakeholders. These required changes are important research topics in both academic and organizational environments. Various studies were conducted to investigate the requirements and success factors for the application of CE frameworks in different industries. Lieder and Rashid (2016) conducted a research to create a comprehensive framework that plays a role as a strategical guide for a successful CE transition process. Their proposed framework lists the economic benefits, resource scarcity, and environmental impact of the CE concept as its three main perspectives, and the research also emphasizes the need for the complete dedication of all stakeholders in the transition process. Smol et al. (2020) aimed to develop and propose a CE model framework for the European waste and wastewater industry in their study by conducting extensive research on the existing literature on CE principles and waste management practices. According to their proposed framework, "reduction", "reclamation", "reuse", recycling", "recovery", and "rethink" are the six actions that help a successful implementation of CE principles in the water and wastewater industry (Smol et al., 2020). Lebre et al. (2017) investigated the compatibility of the CE framework within the mining industry, and they suggested that by applying CE principles, organizations can manage mining waste in a better form and produce added environmental value to the industry. Yadav et al. (2020) developed a framework by combining Industry 4.0 and CE principles to propose a solution to the challenge of sustainable supply chain management in the automotive industry. Adams et al. (2017) questioned the current position, awareness, drivers, and limitations of CE practices comprehensively in the construction industry.

Tourism industry would provide a wide range of possibilities to create value by implementing CE principles, however, the number of academic works have been conducted remains very limited compared to other industries, especially to the manufacturing industry (Rodriguez et al., 2020). A 
International Journal of Mathematical, Engineering and Management Sciences

Vol. 6, No. 3, 824-846, 2021

https://doi.org/10.33889/IJMEMS.2021.6.3.049

project, namely CIRTOINNO, was developed by seven organizations from four South Baltic Region countries in 2016 to encourage the use of innovation in small and medium-sized touristic companies with the help of implementation of CE practices in their operations. The possible CE applications within the accommodation, hotel, restaurant, and spa \& wellness areas are examined in a very detailed manner in the handbook published by the initiative. The handbook defines the increasing amount of traveling and hedonic consumption of the tourists as the main challenges to $\mathrm{CE}$ implementation in the tourism industry. As the tourism industry grows, new destinations and new flight routes come into the picture. The increase in traveling poses a significant threat to environmental sustainability due to increasing carbon emissions coming from fuel consumption. Hedonic consumption of the tourists is a challenge for a successful implementation of CE principles in the tourism industry because people tend to use more in holidays and prefer to use the water and energy in a more unconcerned way (Manniche et al., 2017). Pamfilie et al. (2018) examined the applicability of CE practices in the Romanian hotel industry, and they suggest that the industry is not ready to adopt this new economic model. Sorensen and Baerenholdt (2020) approached the relationship between $\mathrm{CE}$ practices and the tourism industry from a different perspective. They aimed to determine the required practices of tourists instead of determining those of the tourism companies or institutions that accelerate the transition of the tourism industry to a CE model.

\section{Methodology}

This study aims to rank the importance of the barriers to transition to CE that are faced by the tourism industry. In line with this target, the related barriers we used in our analysis were determined by literature review and expert opinions. Then, the pairwise comparison survey form was conducted by a group of experts consisting of industry representatives. Interval Type 2 Fuzzy AHP method was used for the evaluation of the collected data. Fuzzy sets were used in this study since it delivers healthier results in decision making in the environment of uncertainty. Conventional mathematical modeling techniques use absolute data based on numbers. However, in practice, the phenomenon of uncertainty can be faced in any stage of the problem-solving process. People make decisions in uncertain environments of an uncertain world. Uncertainty can reveal itself in the data when verbal expressions have different meanings for different people or when people's perceptions are different (Dereli and Altun, 2013; Kahraman et al., 2014). Uncertainty increases from numbers to words and from word to perceptions (John and Coupland, 2009). Fuzzy sets were first proposed by Zadeh (1965) in order to reduce the uncertainty by modeling verbal expressions or words, while Type 2 fuzzy sets were proposed by Zadeh (1975) again in order to model perceptions (Dereli and Altun, 2013).

In the process of solving a decision-making problem, fuzzy sets are used in order to deal with the uncertainty. Lately, researchers have started to use type- 2 fuzzy sets to overcome different kinds of uncertainty, such as the impossibility of defining membership functions, linguistic differences among people, ambiguity, and lack of information. We can present a type-2 fuzzy set as below (Cebi and Otay, 2015):

$$
\begin{gathered}
\tilde{A}_{i}=\left(\tilde{A}_{i}^{U}, \tilde{A}_{i}^{L}\right) \\
\tilde{A}_{i}^{U}=\left(a_{i 1}^{U}, a_{i 2}^{U}, a_{i 3}^{U}, a_{i 4}^{U} ; H_{1}\left(\tilde{A}_{i}^{U}\right), H_{2}\left(\tilde{A}_{i}^{U}\right)\right), \\
\tilde{A}_{i}^{L}=\left(a_{i 1}^{L}, a_{i 2}^{L}, a_{i 3}^{L}, a_{i 4}^{L} ; H_{1}\left(\tilde{A}_{i}^{L}\right), H_{2}\left(\tilde{A}_{i}^{L}\right)\right), \\
H_{1}\left(\tilde{A}_{i}^{U}\right), H_{2}\left(\tilde{A}_{i}^{U}\right), H_{1}\left(\tilde{A}_{i}^{L}\right), H_{2}\left(\tilde{A}_{i}^{L}\right) \in[0,1] .
\end{gathered}
$$


In the above equation, $\tilde{A}_{i}^{U}$ and $\tilde{A}_{i}^{L}$ represent upper and lower trapezoidal membership functions as in type-1 and $a_{i 1}^{U}, a_{i 2}^{U}, a_{i 3}^{U}, a_{i 4}^{U}, a_{i 1}^{L}, a_{i 2}^{L}, a_{i 3}^{L}, a_{i 4}^{L}$ represent the reference points of type-2 fuzzy numbers. $H_{j}\left(\tilde{A}_{i}^{U}\right)$ and $H_{j}\left(\tilde{A}_{i}^{L}\right)$ are the membership values of $a_{i(j+1)}^{U}$ and $a_{i(j+1)}^{L}$. Figure 1 in the figures section exhibits the membership function of a type-2 fuzzy set $\tilde{A}$ (Cebi and Otay, 2015; Lee and Chen, 2008).

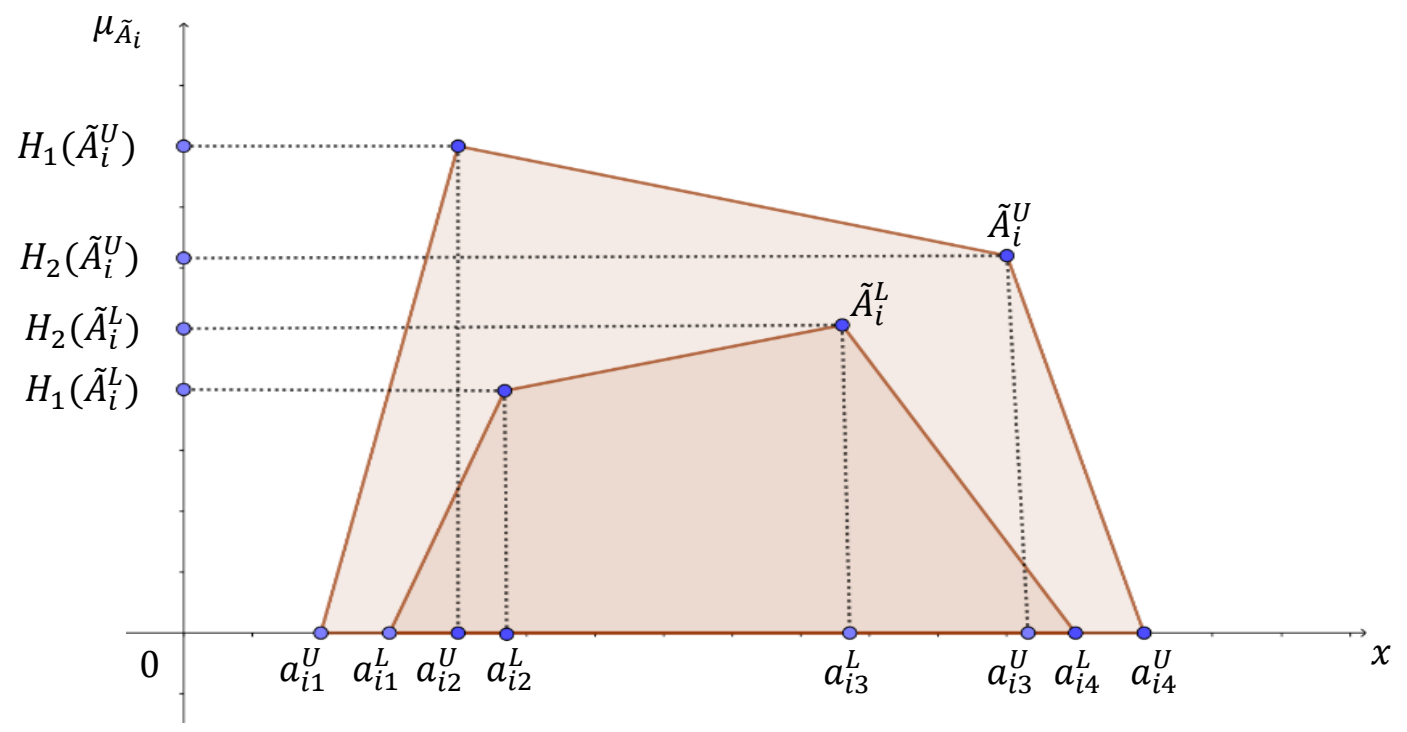

Figure 1. Interval type-2 fuzzy set $\tilde{\text { Â. }}$

The membership functions in type-1 fuzzy sets are two dimensional, while they are three dimensional in type-2 fuzzy sets. The third dimension in type- 2 fuzzy sets plays a vital role in overcoming uncertainty with the degree of freedom it provides.

Interval type-2 fuzzy sets are the most common version of type-2 fuzzy sets. Its most typical characteristics are its simplicity and lower amount of mathematical calculations (Kahraman et al., 2014). Before starting the application, it is necessary to summarize some of the arithmetic operations in interval type-2 fuzzy sets in order to provide a better understanding of the process. When the relevant literature is reviewed, it is seen that the arithmetic operations are summarized before the application part (Ayvaz and Kusakci, 2017; Cebi and Otay, 2015; Chen and Lee, 2010; Deveci et al., 2017; Lee and Chen, 2008). In the next part of the study, first, the arithmetic operations in interval trapezoidal type- 2 fuzzy sets and then the processing steps for interval type 2 fuzzy AHP model will be explained.

\subsection{Arithmetic Operations in Interval Trapezoidal Type 2 Fuzzy Sets}

Definition 3.1.1 Addition operation between two interval trapezoidal type-2 fuzzy sets, $\tilde{A}_{1}$ and $\tilde{A}_{2}$, is defined as; 
International Journal of Mathematical, Engineering and Management Sciences

Vol. 6, No. 3, 824-846, 2021

https://doi.org/10.33889/IJMEMS.2021.6.3.049

$\tilde{\tilde{A}}_{1} \oplus \tilde{\tilde{A}}_{2}=\left(\begin{array}{l}\left(\begin{array}{l}a_{11}^{U}+a_{21}^{U}, a_{12}^{U}+a_{22}^{U}, a_{13}^{U}+a_{23}^{U}, a_{14}^{U}+a_{24}^{U} ; \\ \min \left(H_{1}\left(\tilde{A}_{1}^{U}\right), H_{1}\left(\tilde{A}_{2}^{U}\right)\right), \min \left(H_{2}\left(\tilde{A}_{1}^{U}\right), H_{1}\left(\tilde{A}_{2}^{U}\right)\right)\end{array}\right), \\ \left(\begin{array}{l}a_{11}^{L}+a_{21}^{L}, a_{12}^{L}+a_{22}^{L}, a_{13}^{L}+a_{23}^{L}, a_{14}^{L}+a_{24}^{L} ; \\ \min \left(H_{1}\left(\tilde{A}_{1}^{L}\right), H_{1}\left(\tilde{A}_{2}^{L}\right)\right), \min \left(H_{2}\left(\tilde{A}_{1}^{L}\right), H_{1}\left(\tilde{A}_{2}^{L}\right)\right)\end{array}\right)\end{array}\right)$

where

$$
\tilde{A}_{1}=\left(a_{11}^{U}, a_{12}^{U}, a_{13}^{U}, a_{14}^{U} ; H_{1}\left(\tilde{A}_{1}^{U}\right), H_{2}\left(\tilde{A}_{1}^{U}\right)\right),\left(a_{11}^{L}, a_{12}^{L}, a_{13}^{L}, a_{14}^{L} ; H_{1}\left(\tilde{A}_{1}^{L}\right), H_{2}\left(\tilde{A}_{1}^{L}\right)\right) .
$$

and

$$
\tilde{A}_{2}=\left(a_{21}^{U}, a_{22}^{U}, a_{23}^{U}, a_{24}^{U} ; H_{1}\left(\tilde{A}_{2}^{U}\right), H_{2}\left(\tilde{A}_{2}^{U}\right)\right),\left(a_{21}^{L}, a_{22}^{L}, a_{23}^{L}, a_{24}^{L} ; H_{1}\left(\tilde{A}_{2}^{L}\right), H_{2}\left(\tilde{A}_{2}^{L}\right)\right) .
$$

Definition 3.1.2 Subtraction operation between two interval trapezoidal type- 2 fuzzy sets, $\tilde{A}_{1}$ and $\tilde{A}_{2}$, is defined as;

$$
\tilde{A}_{1}-\tilde{\tilde{A}}_{2}=\left(\begin{array}{l}
\left(\begin{array}{l}
a_{11}^{U}-a_{24}^{U}, a_{12}^{U}-a_{23}^{U}, a_{13}^{U}-a_{22}^{U}, a_{14}^{U}-a_{21}^{U} ; \\
\min \left(H_{1}\left(\tilde{A}_{1}^{U}\right), H_{1}\left(\tilde{A}_{2}^{U}\right)\right), \min \left(H_{2}\left(\tilde{A}_{1}^{U}\right), H_{1}\left(\tilde{A}_{2}^{U}\right)\right)
\end{array}\right), \\
\left(\begin{array}{c}
a_{11}^{L}-a_{24}^{L}, a_{12}^{L}-a_{23}^{L}, a_{13}^{L}-a_{22}^{L}, a_{14}^{L}-a_{21}^{L} ; \\
\min \left(H_{1}\left(\tilde{A}_{1}^{L}\right), H_{1}\left(\tilde{A}_{2}^{L}\right)\right), \min \left(H_{2}\left(\tilde{A}_{1}^{L}\right), H_{1}\left(\tilde{A}_{2}^{L}\right)\right)
\end{array}\right)
\end{array}\right)
$$

where

$$
\tilde{A}_{1}=\left(a_{11}^{U}, a_{12}^{U}, a_{13}^{U}, a_{14}^{U} ; H_{1}\left(\tilde{A}_{1}^{U}\right), H_{2}\left(\tilde{A}_{1}^{U}\right)\right),\left(a_{11}^{L}, a_{12}^{L}, a_{13}^{L}, a_{14}^{L} ; H_{1}\left(\tilde{A}_{1}^{L}\right), H_{2}\left(\tilde{A}_{1}^{L}\right)\right) .
$$

and

$$
\tilde{A}_{2}=\left(a_{21}^{U}, a_{22}^{U}, a_{23}^{U}, a_{24}^{U} ; H_{1}\left(\tilde{A}_{2}^{U}\right), H_{2}\left(\tilde{A}_{2}^{U}\right)\right),\left(a_{21}^{L}, a_{22}^{L}, a_{23}^{L}, a_{24}^{L} ; H_{1}\left(\tilde{A}_{2}^{L}\right), H_{2}\left(\tilde{A}_{2}^{L}\right)\right) .
$$

Definition 3.1.3 Multiplication operation between two interval trapezoidal type-2 fuzzy sets, $\tilde{A}_{1}$ and $\tilde{A}_{2}$, is defined as;

$\tilde{A}_{1} \otimes \tilde{A}_{2}=\left(\begin{array}{l}\left(\begin{array}{l}a_{11}^{U} \times a_{21}^{U}, a_{12}^{U} \times a_{22}^{U}, a_{13}^{U} \times a_{23}^{U}, a_{14}^{U} \times a_{24}^{U} ; \\ \min \left(H_{1}\left(\tilde{A}_{1}^{U}\right), H_{1}\left(\tilde{A}_{2}^{U}\right)\right), \min \left(H_{2}\left(\tilde{A}_{1}^{U}\right), H_{2}\left(\tilde{A}_{2}^{U}\right)\right)\end{array}\right), \\ \left(\begin{array}{l}a_{11}^{L} \times a_{21}^{L}, a_{12}^{L} \times a_{22}^{L}, a_{13}^{L} \times a_{23}^{L}, a_{14}^{L} \times a_{24}^{L} ; \\ \min \left(H_{1}\left(\tilde{A}_{1}^{L}\right), H_{1}\left(\tilde{A}_{2}^{L}\right)\right), \min \left(H_{2}\left(\tilde{A}_{1}^{L}\right), H_{2}\left(\tilde{A}_{2}^{L}\right)\right)\end{array}\right)\end{array}\right)$ 
International Journal of Mathematical, Engineering and Management Sciences

Vol. 6, No. 3, 824-846, 2021

https://doi.org/10.33889/IJMEMS.2021.6.3.049

where

$$
\begin{gathered}
\tilde{A}_{1}=\left(a_{11}^{U}, a_{12}^{U}, a_{13}^{U}, a_{14}^{U} ; H_{1}\left(\tilde{A}_{1}^{U}\right), H_{2}\left(\tilde{A}_{1}^{U}\right)\right),\left(a_{11}^{L}, a_{12}^{L}, a_{13}^{L}, a_{14}^{L} ; H_{1}\left(\tilde{A}_{1}^{L}\right), H_{2}\left(\tilde{A}_{1}^{L}\right)\right) . \text { and } \\
\tilde{A}_{2}=\left(a_{21}^{U}, a_{22}^{U}, a_{23}^{U}, a_{24}^{U} ; H_{1}\left(\tilde{A}_{2}^{U}\right), H_{2}\left(\tilde{A}_{2}^{U}\right)\right),\left(a_{21}^{L}, a_{22}^{L}, a_{23}^{L}, a_{24}^{L} ; H_{1}\left(\tilde{A}_{2}^{L}\right), H_{2}\left(\tilde{A}_{2}^{L}\right)\right) .
\end{gathered}
$$

Definition 3.1.4 Multiplication and division of an interval trapezoidal type-2 fuzzy set, $\tilde{A}_{1}$, with a crisp number $\mathrm{k}$ are defined as follows:

$k \times \tilde{A}_{1}=\left(\begin{array}{l}\left(k \times a_{11}^{U}, k \times a_{12}^{U}, k \times a_{13}^{U}, k \times a_{14}^{U} ; H_{1}\left(\tilde{A}_{1}^{U}\right), H_{2}\left(\tilde{A}_{1}^{U}\right)\right) \\ \left(k \times a_{11}^{L}, k \times a_{12}^{L}, k \times a_{13}^{L}, k \times a_{14}^{L} ; H_{1}\left(\tilde{A}_{1}^{L}\right), H_{2}\left(\tilde{A}_{1}^{L}\right)\right)\end{array}\right)$

$\frac{\tilde{A}_{1}}{k}=\left(\begin{array}{l}\left(\frac{1}{k} \times a_{11}^{U}, \frac{1}{k} \times a_{12}^{U}, \frac{1}{k} \times a_{13}^{U}, \frac{1}{k} \times a_{14}^{U} ; H_{1}\left(\tilde{A}_{1}^{U}\right), H_{2}\left(\tilde{A}_{1}^{U}\right)\right) \\ \left(\frac{1}{k} \times a_{11}^{L}, \frac{1}{k} \times a_{12}^{L}, \frac{1}{k} \times a_{13}^{L}, \frac{1}{k} \times a_{14}^{L} ; H_{1}\left(\tilde{A}_{1}^{L}\right), H_{2}\left(\tilde{A}_{1}^{L}\right)\right)\end{array}\right)$

where $\tilde{A}_{1}=\left(a_{11}^{U}, a_{12}^{U}, a_{13}^{U}, a_{14}^{U} ; H_{1}\left(\tilde{A}_{1}^{U}\right), H_{2}\left(\tilde{A}_{1}^{U}\right)\right),\left(a_{11}^{L}, a_{12}^{L}, a_{13}^{L}, a_{14}^{L} ; H_{1}\left(\tilde{A}_{1}^{L}\right), H_{2}\left(\tilde{A}_{1}^{L}\right)\right)$ and $k>0$.

Definition 3.1.5 Ranking value of a type-2 fuzzy number, $\tilde{A}_{i}$, is as follows where

$$
\tilde{A}_{i}=\left(\tilde{A}_{i}^{U}, \tilde{A}_{i}^{L}\right)=\left(\begin{array}{c}
\left(a_{i 1}^{U}, a_{i 2}^{U}, a_{i 3}^{U}, a_{i 4}^{U} ; H_{1}\left(\tilde{A}_{i}^{U}\right), H_{2}\left(\tilde{A}_{i}^{U}\right)\right), \\
\left(a_{i 1}^{L}, a_{i 2}^{L}, a_{i 3}^{L}, a_{i 4}^{L} ; H_{1}\left(\tilde{A}_{i}^{L}\right), H_{2}\left(\tilde{A}_{i}^{L}\right)\right)
\end{array}\right)
$$

$\operatorname{Rank}\left(\tilde{A}_{i}\right)=M_{1}\left(\tilde{A}_{i}^{U}\right)+M_{1}\left(\tilde{A}_{i}^{L}\right)+M_{2}\left(\tilde{A}_{i}^{U}\right)+M_{2}\left(\tilde{A}_{i}^{L}\right)+M_{3}\left(\tilde{A}_{i}^{U}\right)+M_{3}\left(\tilde{A}_{i}^{L}\right)-$ $\frac{1}{4}\left(S_{1}\left(\tilde{A}_{i}^{U}\right)+S_{1}\left(\tilde{A}_{i}^{L}\right)+S_{2}\left(\tilde{A}_{i}^{U}\right)+S_{2}\left(\tilde{A}_{i}^{L}\right)+S_{3}\left(\tilde{A}_{i}^{U}\right)+S_{4}\left(\tilde{A}_{i}^{L}\right)\right)+H_{1}\left(\tilde{A}_{i}^{U}\right)+H_{1}\left(\tilde{A}_{i}^{L}\right)+$ $H_{2}\left(\tilde{A}_{i}^{U}\right)+H_{2}\left(\tilde{A}_{i}^{L}\right)$

In the equation, $M_{p}\left(\tilde{A}_{i}^{j}\right)$ indicates the average of the elements $a_{i p}^{j}$ and $a_{i(p+1)}^{j}$,

$$
M_{p}\left(\tilde{A}_{i}^{j}\right)=\left(a_{i p}^{j}+a_{i(p+1)}^{j}\right) / 2,1 \leq p \leq 3 .
$$

$S_{q}\left(\tilde{A}_{i}^{j}\right)$, on the other hand, denotes the standard deviations of the elements $a_{i q}^{j}$ and $a_{i(q+1)}^{j}$.

$$
S_{q}\left(\tilde{A}_{i}^{j}\right)=\sqrt{\frac{1}{2} \sum_{k=q}^{q+1}\left(a_{i k}^{j}-\frac{1}{2} \sum_{k=q}^{q+1} a_{i k}^{j}\right)^{2}}, \quad 1 \leq q \leq 3 .
$$

$S_{4}\left(\tilde{A}_{i}^{j}\right)$, gives the standard deviations of the elements $a_{i 1}^{j}, a_{i 2}^{j}, a_{i 3}^{j}$, and $a_{i 4}^{j}$. 
International Journal of Mathematical, Engineering and Management Sciences

Vol. 6, No. 3, 824-846, 2021

https://doi.org/10.33889/IJMEMS.2021.6.3.049

$$
S_{4}\left(\tilde{A}_{i}^{j}\right)=\sqrt{\frac{1}{4} \sum_{k=1}^{4}\left(a_{i k}^{j}-\frac{1}{4} \sum_{k=1}^{4} a_{i k}^{j}\right)^{2}}
$$

$H_{p}\left(\tilde{A}_{i}^{j}\right)$ gives the membership value of the element $a_{i(p+1)}^{j}$ of $\tilde{A}_{i}^{j}$ isosceles trapezoid membership function and there, $1 \leq p \leq 2, \mathrm{j} \in\{U, L\}$, and $1 \leq i \leq n$.

Interval type-2 fuzzy AHP method is used in this study to determine the importance of the criteria. Kahraman et al. (2014) modified Buckley's (1985) type-2 fuzzy AHP model and it is used in this study. The steps of the method are as follows:

Step 1: Fuzzy pairwise comparison matrices for all criteria are set up as shown below:

$$
\begin{gathered}
\tilde{\tilde{A}}=\left[\begin{array}{cccc}
1 & \tilde{\tilde{a}}_{12} & \ldots & \tilde{\tilde{a}}_{1 n} \\
\tilde{\tilde{a}}_{21} & 1 & \ldots & \tilde{\tilde{a}}_{2 n} \\
\vdots & \vdots & \ddots & \vdots \\
\tilde{\tilde{a}}_{n 1} & \tilde{\tilde{a}}_{n 2} & \ldots & 1
\end{array}\right]=\left[\begin{array}{cccc}
1 & \tilde{\tilde{a}}_{12} & \ldots & \tilde{\tilde{a}}_{1 n} \\
1 / \tilde{\tilde{a}}_{21} & 1 & \ldots & \tilde{\tilde{a}}_{2 n} \\
\vdots & \vdots & \ddots & \vdots \\
1 / \tilde{\tilde{a}}_{n 1} & 1 / \tilde{\tilde{a}}_{n 2} & \ldots & 1
\end{array}\right], \quad \text { where } \\
\frac{1}{\tilde{\tilde{a}}}=\left(\left(\frac{1}{a_{14}^{U}}, \frac{1}{a_{13}^{U}}, \frac{1}{a_{12}^{U}}, \frac{1}{a_{11}^{U}} ; H_{1}\left(a_{12}^{U}\right), H_{2}\left(a_{13}^{U}\right)\right), \quad\left(\frac{1}{a_{24}^{L}}, \frac{1}{a_{23}^{L}}, \frac{1}{a_{22}^{L}}, \frac{1}{a_{21}^{L}} ; H_{1}\left(a_{22}^{L}\right), H_{2}\left(a_{23}^{L}\right)\right)\right) .
\end{gathered}
$$

Fuzzy pairwise comparison matrices are set up with the help of linguistic variables of expert opinions. The interval type-2 fuzzy scale (Kahraman et al., 2014) which was used by the experts on pairwise comparisons is shown in Table 1.

Table 1. Definition and interval type-2 fuzzy scales of the linguistic variables.

\begin{tabular}{|l|c|c|}
\hline Linguistic Variables & Triangular interval type-2 fuzzy scales & Trapezoidal interval type-2 fuzzy scales \\
\hline Absolutely Strong (AS) & $(7.5,9,10.5 ; 1)(8.5,9,9.5 ; 0.9)$ & $(7,8,9,9 ; 1,1)(7.2,8.2,8.8,9 ; 0.8,0.8)$ \\
\hline Very Strong (VS) & $(5.5,7,8.5 ; 1)(6.5,7,7.5 ; 0.9)$ & $(5,6,8,9 ; 1,1)(5.2,6.2,7.8,8.8 ; 0.8,0.8)$ \\
\hline Fairly Strong (FS) & $(3.5,5,6.5 ; 1)(4.5,5,5.5 ; 0.9)$ & $(3,4,6,7 ; 1,1)(3.2,4.2,5.8,6.8 ; 0.8,0.8)$ \\
\hline Slightly Strong (SS) & $(1.5,3,4.5 ; 1)(2.5,3,3.5 ; 0.9)$ & $(1,2,4,5 ; 1,1)(1.2,2.2,3.8,4.8 ; 0.8,0.8)$ \\
\hline Exactly Equal (E) & $(1,1,1 ; 1)(1,1,1 ; 1)$ & $(1,1,1,1 ; 1,1)(1,1,1,1 ; 1,1)$ \\
\hline $\begin{array}{l}\text { If factor i has one of the above } \\
\text { linguistic variables assigned to it when } \\
\text { compared with factor j, then j has the } \\
\text { reciprocal value when compared with i }\end{array}$ & Reciprocals of above & \\
\hline
\end{tabular}

Step 2: The consistency of the fuzzy pairwise comparison matrices are investigated. If they are not consistent, the experts are asked to make pairwise comparisons again. In order to perform consistency evaluation, the fuzzy matrix must be defuzzified first. In the defuzzification process, the DTraT model which was suggested by Kahraman et al. (2014) is applied.

$\operatorname{DTraT}=\frac{\left[\frac{\left(u_{U}-l_{U}\right)+\left(\beta_{U} \cdot m_{1 U}-l_{U}\right)+\left(\alpha_{U} \cdot m_{2 U}-l_{U}\right)}{4}+l_{U}\right]+\left[\frac{\left(u_{L}-l_{L}\right)+\left(\beta_{L} \cdot m_{1 L}-l_{L}\right)+\left(\alpha_{L} \cdot m_{2 L}-l_{L}\right)}{4}+l_{L}\right]}{2}$ 
where $\alpha$ and $\beta$ denote the maximum membership degrees of the lower membership function of the type-2 fuzzy set; $u_{U}$ denotes the largest possible value of the upper membership function; $l_{U}$ denotes the least possible value of the upper membership function; $m_{1 U}$ and $m_{2 U}$ denote the second and third parameters of the upper membership function; $u_{L}$ denotes the largest possible value of the lower membership function; $l_{L}$ denotes the least possible value of the lower membership function; $m_{1 L}$ and $m_{2 L}$ denote the second and third parameters of the lower membership function, respectively.

After completing the defuzzification process with the DTraT method, the consistency procedure used in the classical AHP method is performed. According to the model suggested by Saaty and Vargas (2012), the steps for the consistency test of a given pairwise comparison matrix A is given

below where $A=\left|\begin{array}{cccc}1 & a_{12} & \ldots & a_{1 n} \\ 1 / a_{12} & 1 & \ldots & a_{2 n} \\ \vdots & \vdots & 1 & \vdots \\ 1 / a_{1 n} & 1 / a_{2 n} & \ldots & 1\end{array}\right|$ and $\mathrm{n}$ is the number of criteria.

First, normalized decision matrix B is determined by normalizing A, where $b_{i j}=\frac{a_{i j}}{\sum_{i=1}^{n} a_{i j}}$. Then, the arithmetic mean of the elements of each row in the normalized decision matrix B is calculated, and it gives the weight vector, $\mathrm{W}$ :

$W=\frac{\sum_{i=1}^{n} b_{i j}}{n}$

After finding the weight vector $\mathrm{W}$, the cross product of $\mathrm{A}$ and $\mathrm{W}$ is calculated, and each row of the calculated $(\mathrm{A} \times \mathrm{W})$ column vector is divided by the corresponding row of $\mathrm{W}$. The arithmetic mean is called as $\lambda_{\max }$.

The following step for the consistency test is the calculation of consistency index (CI) and consistency ratio (CR):

$C I=\frac{\lambda_{\max }-n}{n-1}$

$C R=\frac{C I}{R I}$

where RI denotes random index which is derived by using $1 / 9,1 / 8, \ldots \ldots, 1, \ldots . .8,9$ scale. Random Index table for the first 10 criteria is exhibited in Table 2. A CR value that is less than 0.10 means the pairwise comparison matrix is consistent and can be used for the analysis.

Table 2. Random index table.

\begin{tabular}{|l|c|c|c|c|c|c|c|c|c|c|}
\hline $\boldsymbol{n}$ & $\mathbf{1}$ & $\mathbf{2}$ & $\mathbf{3}$ & $\mathbf{4}$ & $\mathbf{5}$ & $\mathbf{6}$ & $\mathbf{7}$ & $\mathbf{8}$ & $\mathbf{9}$ & $\mathbf{1 0}$ \\
\hline RI & 0 & 0 & 0.58 & 0.9 & 1.12 & 1.24 & 1.32 & 1.41 & 1.45 & 1.49 \\
\hline
\end{tabular}


Step 3: Geometric mean of each row is calculated by using the equation 11:

$\tilde{\tilde{r}}_{i}=\left[\tilde{\tilde{a}}_{i 1} \otimes \ldots \otimes \tilde{\tilde{a}}_{i n}\right]^{1 / n}$

where

$$
\begin{gathered}
\sqrt[n]{\tilde{\tilde{a}}_{i j}}=\left(\left(\sqrt[n]{a_{i j 1}^{U},} \sqrt[n]{a_{i j 2}^{U},} \sqrt[n]{a_{i j 3}^{U},} \sqrt[n]{a_{i j 4}^{U} ;} ; H_{1}^{u}\left(a_{i j}\right), H_{2}^{u}\left(a_{i j}\right)\right),\right. \\
\left.\left(\sqrt[n]{a_{i j 1}^{L},} \sqrt[n]{a_{i j 2}^{L},} \sqrt[n]{a_{i j 3}^{L},} \sqrt[n]{a_{i j 4}^{L}} ; H_{1}^{L}\left(a_{i j}\right), H_{2}^{L}\left(a_{i j}\right)\right)\right) .
\end{gathered}
$$

Step 4: Fuzzy weights of each criterion is calculated by using the equation 12 :

$\tilde{w}_{i}=\tilde{r} \otimes\left[\tilde{r} \oplus \ldots \oplus \tilde{r}_{i} \oplus \ldots \oplus \tilde{r}_{n}\right]^{-1}$

where

$$
\begin{gathered}
\frac{\tilde{a}_{i j}}{\tilde{\tilde{b}}_{i j}}=\left(\frac{a_{1}^{u}}{b_{4}^{u}}, \frac{a_{2}^{u}}{b_{3}^{u}}, \frac{a_{3}^{u}}{b_{2}^{u}}, \frac{a_{4}^{u}}{b_{1}^{u}} ; \min \left(H_{1}^{u}(a), H_{1}^{u}(b)\right), \min \left(H_{2}^{u}(a), H_{2}^{u}(b)\right)\right), \\
\left(\frac{a_{1}^{L}}{b_{4}^{L}}, \frac{a_{2}^{L}}{b_{3}^{L}}, \frac{a_{3}^{L}}{b_{2}^{L}}, \frac{a_{4}^{L}}{b_{1}^{L}} ; \min \left(H_{1}^{L}(a), H_{1}^{L}(b)\right), \min \left(H_{2}^{L}(a), H_{2}^{L}(b)\right)\right) .
\end{gathered}
$$

Step 5: Fuzzy performance score is calculated by using the equation 13

$$
\tilde{U}_{i}=\sum_{j=1}^{n} \tilde{w}_{j} \tilde{r}_{i j}, \forall i
$$

where $\tilde{U}_{i}$ denotes the fuzzy utility of alternative $i$; $\tilde{w}_{j}$ denotes the weight of the criterion $j$, and $\tilde{r}_{i j}$ denotes the performance score of alternative $i$ with respect to criterion $j$.

Step 6: Fuzzy numbers are defuzzified in order to determine the rank of alternatives, and then the ranking is decided.

\section{Application}

In this study, the barriers to the transition to CE in the tourism industry are evaluated. Transition to $\mathrm{CE}$ is considered as an unavoidable transformation for manufacturing companies in order to reach a sustainable economic environment (Kazancoglu et al., 2020). The tourism industry acts as an essential driver for the growth and prosperity of the countries, yet, it also creates serious negative environmental issues since it uses lands, consumes water, food, and energy resources, creates waste, and pollutes the environment (Rodriguez et al., 2020). We chose the tourism industry because of its importance on the economy and the lack of studies covering the relationship between $\mathrm{CE}$ and the industry. 
International Journal of Mathematical, Engineering and Management Sciences

Vol. 6, No. 3, 824-846, 2021

https://doi.org/10.33889/IJMEMS.2021.6.3.049

The barriers used in the application were determined by reviewing the existing literature and interviewing experts from the industry. The evaluation of the barriers was conducted by the expert opinions. The aim of this study is to evaluate and rank the barriers to transition to CE in the tourism industry hierarchically according to their importance. With the help of this study, the industry will be able to determine its primary study areas for transition to CE. The Interval Type 2 Fuzzy AHP method was used, and the survey was conducted with 4 experts working as general managers at different 5-star hotels in the Mediterranean region of Turkey. The conceptual framework of the study is exhibited in Figure 2.

An extensive set of barriers to transition to $\mathrm{CE}$ was put together after a comprehensive literature review for the application stage. Then, the most relevant barriers for the tourism industry were determined with the help of experts from the industry and ten of them were selected. These barriers are "lack of governmental support (B1)" (Farooque et al., 2019; Govindan et al., 2014; Rizos et al., 2016), "complexity of CE friendly product designs (B2)" (Govindan et al., 2014; Ritzen \& Sandstrom, 2017), "lack of new technologies, materials and processes (B3)" (Farooque et al., 2019; Govindan et al., 2014; Rizos et al., 2016), "high initial investment costs and/or low returns (B4)" (Agyemang et al., 2019; Farooque et al., 2019; Govindan et al., 2014; Kirchherr et al., 2018; Masi et al., 2018; Ritzen \& Sandstrom, 2017), "cost of environmental friendly packaging(B5)" (Govindan et al., 2014), "additional human resource needs (B6)" (Govindan et al., 2014), "lack of knowledge and training possibilities (B7)" (Govindan et al., 2014), "lack of awareness/preference/pressure of the consumers (B8)" (Farooque et al., 2019; Galvao et al., 2018; Govindan et al., 2014; Govindan and Hasanagic, 2018; Kirchherr et al., 2018), "lack of corporate social responsibility (B9)" (Govindan et al., 2014), and "organizational structure/infrastructure that creates inconvenience with supply chain on transition to CE (B10)" (Farooque et al., 2019; Govindan and Hasanagic, 2018; Ritzen and Sandstrom, 2017).

In the first step of the application, the experts were asked to fill a pairwise comparison survey consisting of linguistic variables. Their linguistic expressions were transformed into fuzzy variables using the interval type-2 fuzzy scale mentioned earlier in Table 1 , and these fuzzy variables constructed the pairwise comparison matrix exhibited in Table 3. 
International Journal of Mathematical, Engineering and Management Sciences

Vol. 6, No. 3, 824-846, 2021

https://doi.org/10.33889/IJMEMS.2021.6.3.049

\section{Literature Review}

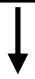

Identification of Barriers to CE

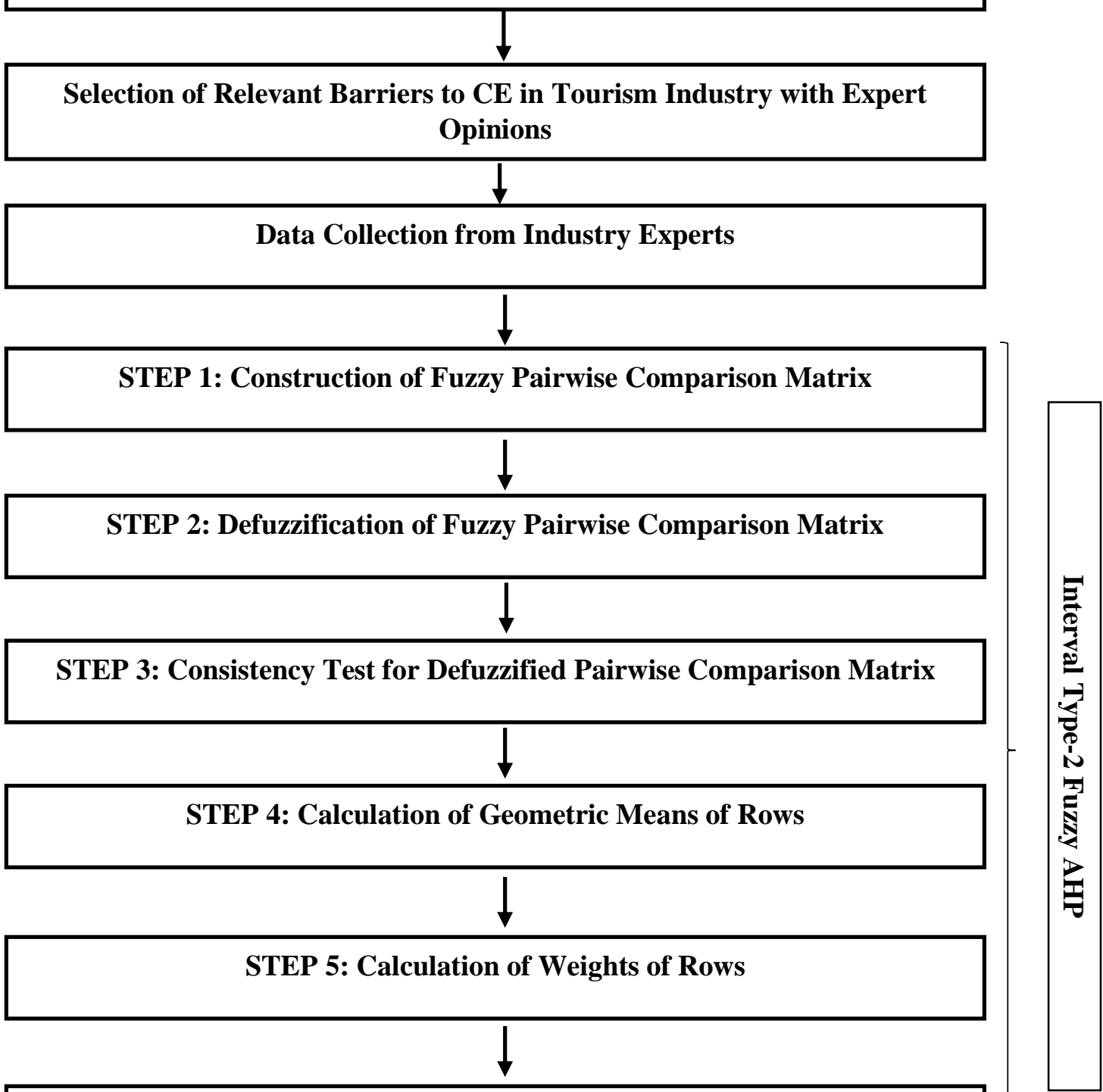

STEP 6: Defuzzification of Weights of Barriers

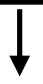

\section{Discussion}

Figure 2. Conceptual framework. 
International Journal of Mathematical, Engineering and Management Sciences

Vol. 6, No. 3, 824-846, 2021

https://doi.org/10.33889/IJMEMS.2021.6.3.049

Table 3. Fuzzy pairwise comparison matrix.

\begin{tabular}{|c|c|c|c|c|c|c|c|c|c|c|}
\hline & $\bar{\theta}$ & $\tilde{\theta}$ & $\Leftrightarrow$ & I & $\Leftrightarrow$ & $\because$ & $\hat{\theta}$ & $\stackrel{\infty}{\infty}$ & $\hat{\theta}$ & $\stackrel{\mathscr{0}}{*}$ \\
\hline$\sqrt{0}$ & 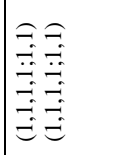 & 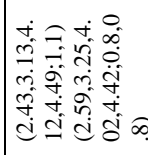 & 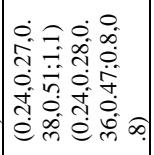 & 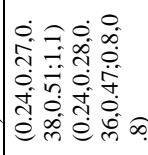 & 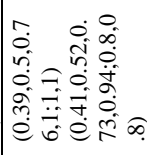 & 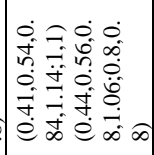 & 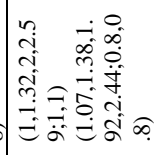 & 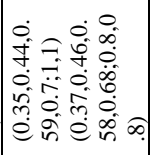 & 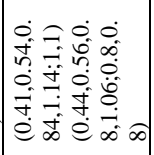 & 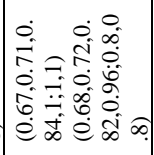 \\
\hline 6 & 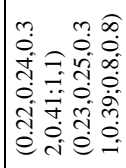 & $\begin{array}{ll}0= \\
0=0 \\
0=0\end{array}$ & 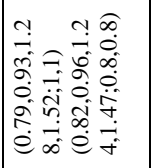 & 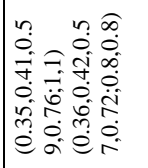 & 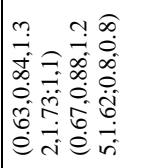 & 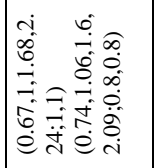 & 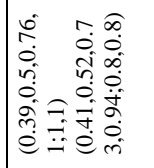 & 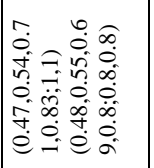 & 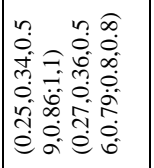 & 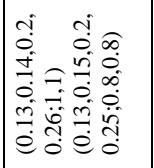 \\
\hline$\theta$ & 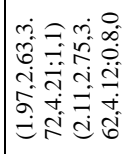 & 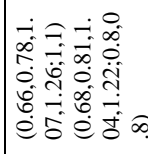 & 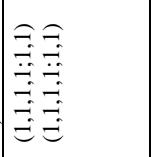 & 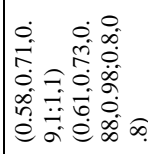 & 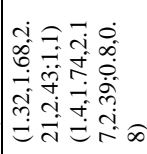 & 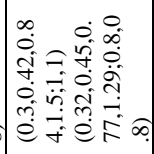 & 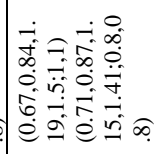 & $\begin{array}{l}\dot{0} \\
\infty \\
0 \\
\dot{0} \\
\dot{d} \\
\dot{-1} \\
=\infty\end{array}$ & 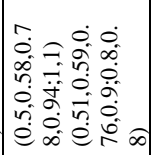 & 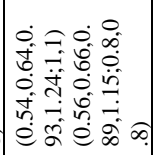 \\
\hline 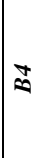 & 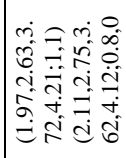 & 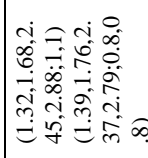 & 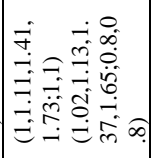 & 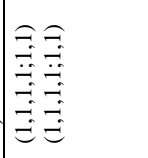 & 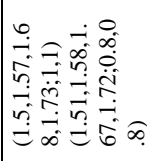 & 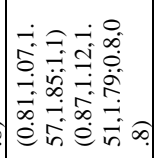 & 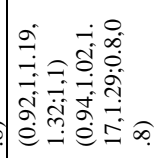 & 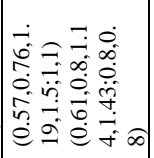 & 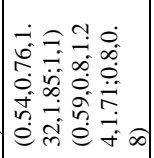 & 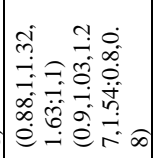 \\
\hline 6 & 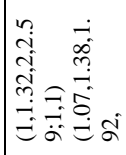 & 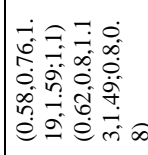 & 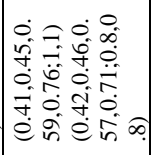 & 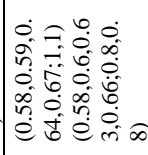 & $\begin{array}{l}=0 \\
=0 \\
=0 \\
=0 \\
=0 \\
=0\end{array}$ & 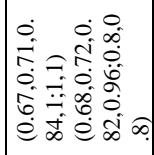 & 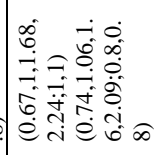 & 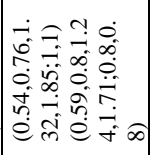 & 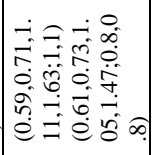 & 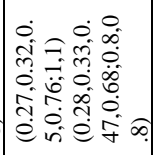 \\
\hline 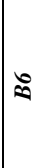 & 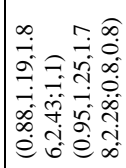 & 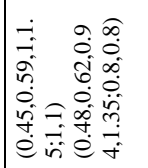 & 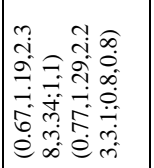 & 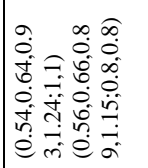 & 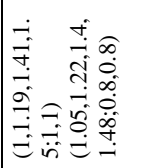 & 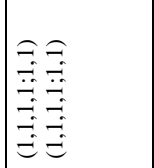 & 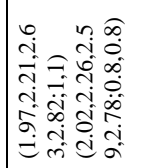 & 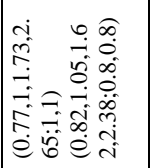 & 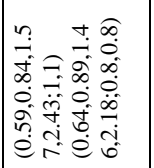 & 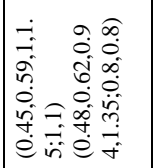 \\
\hline$\hat{\theta}$ & 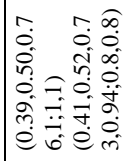 & 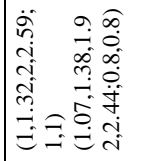 & 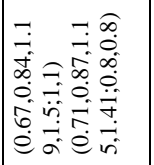 & 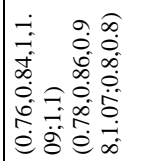 & 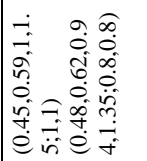 & 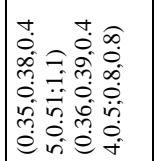 & 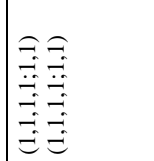 & 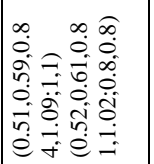 & 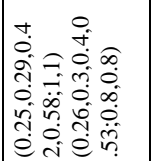 & 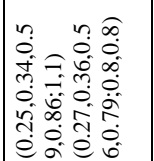 \\
\hline$\stackrel{8}{\circ}$ & 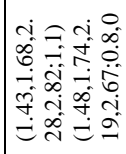 & 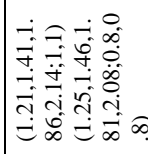 & 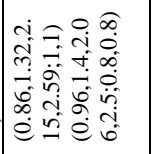 & 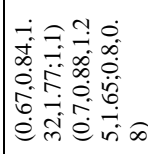 & 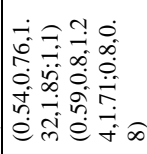 & 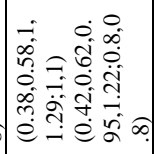 & 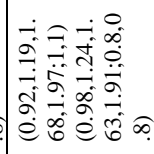 & $\begin{array}{ll} & = \\
= & = \\
= & =1 \\
= & =1 \\
= & =1\end{array}$ & 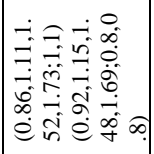 & 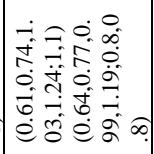 \\
\hline 8 & 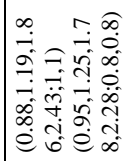 & 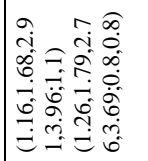 & 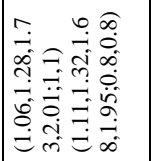 & 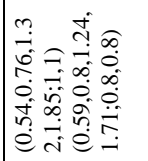 & 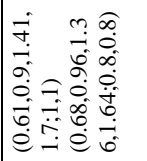 & 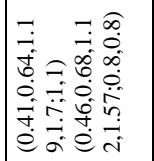 & 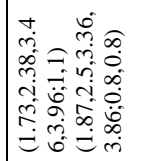 & 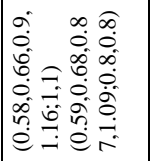 & 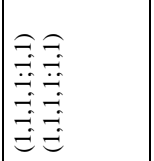 & 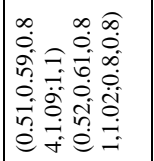 \\
\hline 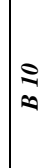 & 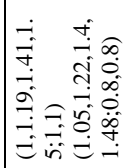 & 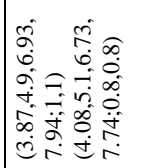 & 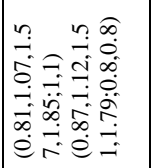 & 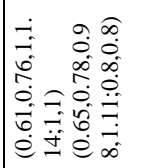 & 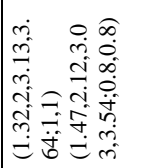 & 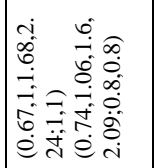 & 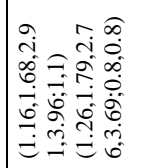 & 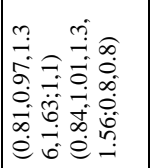 & 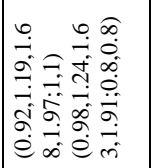 & 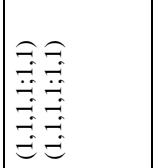 \\
\hline
\end{tabular}


International Journal of Mathematical, Engineering and Management Sciences

Vol. 6, No. 3, 824-846, 2021

https://doi.org/10.33889/IJMEMS.2021.6.3.049

5

20

Table 4. Defuzzified pairwise comparison matrix.

\begin{tabular}{|c|c|c|c|c|c|c|c|c|c|c|}
\hline & B1 & B2 & B3 & B4 & B5 & B6 & B7 & B8 & B9 & B10 \\
\hline B1 & 1.00 & 3.37 & 0.33 & 0.33 & 0.62 & 0.69 & 1.63 & 0.50 & 0.69 & 0.76 \\
\hline B2 & 0.30 & 1.00 & 1.07 & 0.50 & 1.06 & 1.32 & 0.62 & 0.60 & 0.48 & 0.17 \\
\hline B3 & 3.05 & 0.93 & 1.00 & 0.76 & 1.82 & 0.71 & 0.99 & 0.65 & 0.66 & 0.79 \\
\hline $\mathbf{B 4}$ & 3.05 & 2.01 & 1.32 & 1.00 & 1.54 & 1.26 & 1.05 & 0.95 & 1.05 & 1.14 \\
\hline B5 & 1.60 & 0.94 & 0.55 & 0.65 & 1.00 & 0.76 & 1.32 & 1.05 & 0.94 & 0.43 \\
\hline B6 & 1.45 & 0.76 & 1.42 & 0.80 & 1.32 & 1.00 & 2.29 & 1.44 & 1.27 & 0.83 \\
\hline $\mathbf{B 7}$ & 0.61 & 1.60 & 1.01 & 0.95 & 0.76 & 0.44 & 1.00 & 0.71 & 0.36 & 0.48 \\
\hline B8 & 2.02 & 1.66 & 1.55 & 1.05 & 0.95 & 0.70 & 1.40 & 1.00 & 1.24 & 0.86 \\
\hline $\mathbf{B 9}$ & 1.45 & 2.08 & 1.51 & 0.95 & 1.06 & 0.79 & 2.77 & 0.81 & 1.00 & 0.71 \\
\hline $\mathbf{B 1 0}$ & 1.32 & 5.79 & 1.27 & 0.88 & 2.31 & 1.21 & 2.08 & 1.17 & 1.40 & 1.00 \\
\hline
\end{tabular}

After the defuzzification process, consistency test of the defuzzified matrix was conducted, and the consistency ratio (CR) was found to be 0.05 , which means that the pairwise comparison matrix is consistent. Table 5 exhibits the related calculations.

Table 5. Consistency test.

\begin{tabular}{|c|c|c|c|c|c|c|c|c|c|c|c|c|c|c|c|}
\hline & B1 & B2 & B3 & B4 & B5 & B6 & B7 & B8 & B9 & B10 & $\mathbf{W}$ & $\bar{A} * \mathbf{W}$ & $\left(A^{*} * \mathbf{W}\right) / \mathbf{W}$ & CI & CR \\
\hline B1 & 0.06 & 0.17 & 0.03 & 0.04 & 0.05 & 0.08 & 0.11 & 0.06 & 0.08 & 0.11 & 0.08 & 0.86 & 11.05 & \multirow{10}{*}{0.08} & \multirow{10}{*}{0.05} \\
\hline B2 & 0.02 & 0.05 & 0.10 & 0.06 & 0.09 & 0.15 & 0.04 & 0.07 & 0.05 & 0.02 & 0.06 & 0.68 & 10.49 & & \\
\hline B3 & 0.19 & 0.05 & 0.09 & 0.10 & 0.15 & 0.08 & 0.07 & 0.07 & 0.07 & 0.11 & 0.10 & 1.05 & 10.78 & & \\
\hline B4 & 0.19 & 0.10 & 0.12 & 0.13 & 0.12 & 0.14 & 0.07 & 0.11 & 0.12 & 0.16 & 0.13 & 1.35 & 10.78 & & \\
\hline B5 & 0.10 & 0.05 & 0.05 & 0.08 & 0.08 & 0.09 & 0.09 & 0.12 & 0.10 & 0.06 & 0.08 & 0.86 & 10.60 & & \\
\hline B6 & 0.09 & 0.04 & 0.13 & 0.10 & 0.11 & 0.11 & 0.15 & 0.16 & 0.14 & 0.12 & 0.11 & 1.20 & 10.49 & & \\
\hline B7 & 0.04 & 0.08 & 0.09 & 0.12 & 0.06 & 0.05 & 0.07 & 0.08 & 0.04 & 0.07 & 0.07 & 0.74 & 10.66 & & \\
\hline B8 & 0.13 & 0.08 & 0.14 & 0.13 & 0.08 & 0.08 & 0.09 & 0.11 & 0.14 & 0.12 & 0.11 & 1.18 & 10.69 & & \\
\hline B9 & 0.09 & 0.10 & 0.14 & 0.12 & 0.09 & 0.09 & 0.18 & 0.09 & 0.11 & 0.10 & 0.11 & 1.19 & 10.70 & & \\
\hline B10 & 0.08 & 0.29 & 0.12 & 0.11 & 0.19 & 0.14 & 0.14 & 0.13 & 0.15 & 0.14 & 0.15 & 1.61 & 10.90 & & \\
\hline & & & & & & & & & & & & & $\begin{array}{c}\lambda_{\max }= \\
10.72\end{array}$ & & \\
\hline
\end{tabular}

After checking the consistency of the pairwise comparison matrix, the geometric means of each row of the matrix were calculated, which are exhibited in Table 6, and then the weights of each barrier were calculated which are also exhibited in Table 7. 
International Journal of Mathematical, Engineering and Management Sciences

Vol. 6, No. 3, 824-846, 2021

https://doi.org/10.33889/IJMEMS.2021.6.3.049

31

32

33

34

35

36

37

38

39

40

41

42

43

44

\begin{tabular}{|c|c|}
\hline Barrier & Score \\
\hline B1 & $8.08 \%$ \\
\hline B2 & $6.45 \%$ \\
\hline B3 & $10.45 \%$ \\
\hline B4 & $13.91 \%$ \\
\hline B5 & $9.06 \%$ \\
\hline B6 & $13.06 \%$ \\
\hline B7 & $7.62 \%$ \\
\hline B8 & $12.81 \%$ \\
\hline B9 & $13.21 \%$ \\
\hline B10 & $16.42 \%$ \\
\hline
\end{tabular}

Table 6. Geometric means of rows.

\begin{tabular}{|c|c|}
\hline$\tilde{\boldsymbol{r}}_{i}$ & Values \\
\hline$\tilde{\boldsymbol{r}}_{1}$ & $(0.54,0.65,0.89,1.1 ; 1,1)(0.56,0.67,0.86,1.05 ; 0.8,0.8)$ \\
\hline$\tilde{\boldsymbol{r}}_{2}$ & $(0.41,0.5,0.72,0.9 ; 1,1)(0.43,0.52,0.69,0.85 ; 0.8,0.8)$ \\
\hline$\tilde{\boldsymbol{r}}_{3}$ & $(0.68,0.83,1.16,1.44 ; 1,1)(0.71,0.86,1.12,1.37 ; 0.8,0.8)$ \\
\hline$\tilde{\boldsymbol{r}}_{4}$ & $(0.97,1.17,1.56,1.82 ; 1,1)(1.02,1.21,1.51,1.76 ; 0.8,0.8)$ \\
\hline$\tilde{\boldsymbol{r}}_{5}$ & $(0.59,0.71,0.99,1.27 ; 1,1)(0.62,0.73,0.96,1.19 ; 0.8,0.8)$ \\
\hline$\tilde{\boldsymbol{r}}_{6}$ & $(0.75,0.97,1.45,1.9 ; 1,1)(0.8,1.01,1.39,1.78 ; 0.8,0.8)$ \\
\hline$\tilde{\boldsymbol{r}}_{7}$ & $(0.5,0.6,0.84,1.06 ; 1,1)(0.52,0.62,0.81,1 ; 0.8,0.8)$ \\
\hline$\tilde{\boldsymbol{r}}_{8}$ & $(0.79,1.01,1.45,1.76 ; 1,1)(0.84,1.05,1.4,1.68 ; 0.8,0.8)$ \\
\hline$\tilde{\boldsymbol{r}}_{9}$ & $(0.77,1,1.49,1.87 ; 1,1)(0.82,1.05,1.43,1.77 ; 0.8,0.8)$ \\
\hline$\tilde{\boldsymbol{r}}_{10}$ & $(1.04,1.34,1.87,2.19 ; 1,1)(1.1,1.39,1.82,2.12 ; 0.8,0.8)$ \\
\hline
\end{tabular}

Table 7. Weights of rows.

\begin{tabular}{|c|c|}
\hline$\tilde{\boldsymbol{W}}_{\boldsymbol{i}}$ & Values \\
\hline$\tilde{\boldsymbol{w}}_{1}$ & $(0.04,0.05,0.1,0.16 ; 1,1)(0.04,0.06,0.09,0.14 ; 0.8,0.8)$ \\
\hline$\tilde{\boldsymbol{W}}_{2}$ & $(0.03,0.04,0.08,0.13 ; 1,1)(0.03,0.04,0.08,0.11 ; 0.8,0.8)$ \\
\hline$\tilde{\boldsymbol{W}}_{3}$ & $(0.04,0.07,0.13,0.2 ; 1,1)(0.05,0.07,0.12,0.18 ; 0.8,0.8)$ \\
\hline$\tilde{\boldsymbol{W}}_{4}$ & $(0.06,0.09,0.18,0.26 ; 1,1)(0.07,0.1,0.17,0.24 ; 0.8,0.8)$ \\
\hline$\tilde{\boldsymbol{W}}_{5}$ & $(0.04,0.06,0.11,0.18 ; 1,1)(0.04,0.06,0.1,0.16 ; 0.8,0.8)$ \\
\hline$\tilde{\boldsymbol{W}}_{\mathbf{6}}$ & $(0.05,0.08,0.17,0.27 ; 1,1)(0.05,0.08,0.15,0.24 ; 0.8,0.8)$ \\
\hline$\tilde{\boldsymbol{W}}_{7}$ & $(0.03,0.05,0.1,0.15 ; 1,1)(0.04,0.05,0.09,0.13 ; 0.8,0.8)$ \\
\hline$\tilde{\boldsymbol{W}}_{8}$ & $(0.05,0.08,0.17,0.25 ; 1,1)(0.06,0.09,0.15,0.23 ; 0.8,0.8)$ \\
\hline$\tilde{\boldsymbol{W}}_{9}$ & $(0.05,0.08,0.17,0.26 ; 1,1)(0.06,0.09,0.16,0.24 ; 0.8,0.8)$ \\
\hline$\tilde{\boldsymbol{w}}_{10}$ & $(0.07,0.11,0.21,0.31 ; 1,1)(0.08,0.12,0.2,0.29 ; 0.8,0.8)$ \\
\hline
\end{tabular}

In the final step, the weights of each barrier were defuzzified to put them in an order according to their scores, as in Table 8.

Table 8. Scores of barriers.
45

46

47

48

49 
International Journal of Mathematical, Engineering and Management Sciences

Vol. 6, No. 3, 824-846, 2021

https://doi.org/10.33889/IJMEMS.2021.6.3.049

50

51

52

53

54

55

56

57

58

59

60

61

62

63

64

65

66

67

68

69

70

71

72

73

74

75

76

77

78

79

80

81

82

83

84

85

86

87

88

89

90

91

92

93

94

95

96

97

\section{Results and Discussion}

According to the results of the study, the most important barrier to transition to CE in the tourism industry is "organizational structure/infrastructure that creates inconvenience with supply chain on transition to CE". This barrier has the highest weight amongst all ten barriers, with a weight of $16.4 \%$. A successful transition to CE requires the participation and engagement of every actor in a supply chain (de Jesus and Mendonca, 2018). As De Angelis et al. (2018) state, existing supply chains are mostly in linear shape with the spread of globalization that makes it possible to use resources from different regions of the world. Therefore, when a company changes its process designs to a more compatible structure with $\mathrm{CE}$ principles, it may face certain incompatibility problems with the existing supply chain if the other actors are not involved in the process sufficiently. This probability seems leading tourism companies to turn a blind eye to CE transition, according to the results. Overcoming this barrier might require increasing the awareness and participation of the actors of the supply chain in the tourism industry.

The second most important barrier to the transition to $\mathrm{CE}$ according to the result of the study is "high initial investment costs and/or low returns" with a $13.9 \%$ weight. It can be inferred that the industry experts think the changes for a $\mathrm{CE}$ transition require a big budget for the companies, and they also think the potential benefits of this transition are not lucrative enough compared to the money invested in at the moment. This result also supports the findings of Agyemang et al. (2019), suggesting that the firms think the up-front investment for the transition to CE would be high since it means reshaping a built facility when the CE practices were not even existing.

"Lack of corporate social responsibility" showed up as the third most important barrier with a weight of $13.2 \%$. Corporate social responsibility is a popular concept among private sector companies which helps them to be accountable in social aspects. It is considered an important factor for companies to find their places in society and embrace social and ethical standards in their operations. The adoption of corporate social responsibility principles by the companies increases every year, yet, many companies still have a long way to go for a serious action towards the concept (Lindgreen and Swaen, 2010). Corporate social responsibility is related to the transition to CE in tourism because it supports the responsible tourism concept and encourages actions like saving water, producing lower $\mathrm{CO}_{2}$ emissions, and decreasing energy consumption (Vargas-Sanchez, 2018). The expert opinions show that the adoption of corporate social responsibility practices is not at a sufficient level in the tourism industry to successfully support a transition to $\mathrm{CE}$ and other environment-friendly practices.

The fourth most important barrier is "additional human resource needs" for the transition process with a weight of $13.1 \%$. Govindan et al. (2014) argue that companies will need extra human resources to implement a transition to green supply chain management practices. Agyemang et al. (2019) suggest that the companies find it expensive to hire qualified employees, which helps the companies to support CE transition. The result of our study supports these claims since we can infer that the experts from the tourism industry think they would need additional workers if they adopt CE practices, and the difficulty of recruitment and the cost of additional employees push them away from implementing $\mathrm{CE}$ principles.

"Lack of awareness/preference/pressure of the consumers" is the fifth most important barrier to CE transition in the tourism industry, with a weight of $12.8 \%$. CE transition needs efforts and participation of all possible actors of the existing supply chain, and consumers are an important part of it (Lieder and Rashid, 2016; Rizos et al., 2016). It is seen that the industry experts think the 
International Journal of Mathematical, Engineering and Management Sciences

Vol. 6, No. 3, 824-846, 2021

https://doi.org/10.33889/IJMEMS.2021.6.3.049

low awareness level of consumers about CE principles makes it difficult to implement CE principles in the tourism industry.

"Lack of new technologies, materials and processes", "cost of environmental friendly packaging", "lack of governmental support", "lack of knowledge and training possibilities", "complexity of CE friendly product designs" are the sixth, seventh, eighth, ninth and tenth important barriers with weights of $10.4 \%, 9.1 \%, 8.1 \%, 7.6 \%, 6.4 \%$ respectively.

\section{Conclusion}

Transition to $\mathrm{CE}$ is of growing interest in the academic environment in recent years, yet, the studies about the barriers to CE implementation in the service industry and, more specifically, in the tourism industry are not sufficient. We intended to understand and present the challenges of the CE transition in the tourism industry to display the current situation and help the stakeholders and the actors in the industry in their actions towards a more circular tourism environment. Positive externalities coming from the application of CE practices would create a significant competitive advantage in the levels of industries and countries. We think that the results will help all the stakeholders within the industrial environment allocate their resources and efforts more efficiently, in line with the aim of establishing a more circular and more sustainable tourism industry.

We believe that relating the CE exclusively with the manufacturing industry limits the benefits of this novel economic model. We hope this study will raise the interest in the possible contributions of CE practices in the service industry and specifically the tourism industry. The drivers and enablers of the CE transition in the service business and the tourism industry can be the main subjects for future research. The relationship of the other industries under the service business can also be examined in a more detailed approach in the following studies. Transition to CE in the tourism industry would be examined in detail by breaking down the tourism industry into accommodation, food, and spa \& wellness industries. As the number of organizations that adopt $\mathrm{CE}$ practices on their business processes increase, performance evaluations of these organizations would open a new field of research in the not-too-far future.

In our study, we faced certain limitations. Since the CE is a novel model and is not yet a known concept in the Turkish tourism industry, finding industry experts who have sufficient knowledge about the CE was difficult. Therefore, we were able to conduct our study with only four industry experts. As the understanding of CE expands in the tourism industry, we will be able to work with a higher number and experts and the accuracy of the findings would increase.

\section{Conflict of Interest}

The authors confirm that there is no conflict of interest to declare for this publication.

\section{Acknowledgments}

This research did not receive any specific grant from funding agencies in the public, commercial, or not-for-profit sectors. The authors would like to thank the editor and anonymous reviewers for their comments that help improve the quality of this work. 
International Journal of Mathematical, Engineering and Management Sciences

Vol. 6, No. 3, 824-846, 2021

https://doi.org/10.33889/IJMEMS.2021.6.3.049

\section{References}

Adams, K.T., Osmani, M., Thorpe, T., \& Thornback, J. (2017). Circular economy in construction: current awareness, challenges and enablers. Waste and Resource Management, 170(WR1), 15-24.

Agyemang, M., Kusi-Sarpong, S., Kahn, S.A., Mani, V., Rehman, S.T., \& Kusi-Sarpong, H. (2019). Drivers and barriers to circular economy implementation: an explorative study in Pakistan's automobile industry. Management Decision, 57(4), 971-994.

Andersen, M.S. (2007). An introductory note on the environmental economics of the circular economy. Sustainability Science, 2(1), 133-140.

Andrews, D. (2015). The circular economy, design thinking and education for sustainability. Local Economy, $30(3), 305-315$.

Ayvaz, B., \& Kusakci, A.O. (2017). A trapezoidal type-2 fuzzy multi-criteria decision making method based on TOPSIS for supplier selection: an application in textile sector. Pamukkale University Journal of Engineering Sciences, 23(1), 70-79.

Blomsma, F., \& Tennant, M. (2020). Circular economy: preserving materials or products? Introducing the resource states framework. Resources, Conservation and Recycling, 156(May 2020), 104698.

Buckley, J.J. (1985). Fuzzy hierarchical analysis. Fuzzy Sets and Systems, 17(3), 233-247.

Cebi, F., \& Otay, I. (2015). Multi-criteria and multi-stage facility location selection under interval type-2 fuzzy environment: a case study for a cement factory. International Journal of Computational Intelligence Systems, 8(2), 330-344.

Chen, S.M., \& Lee, L.W. (2010). Fuzzy multiple attributes group decision-making based on the ranking values and the arithmetic operations of interval type-2 fuzzy sets. Expert Systems with Applications, 37(1), 824-833.

De Angelis, R., Howard, M., \& Miemczyk, J. (2018). Supply chain management and the circular economy: towards the circular supply chain. Production Planning \& Control, 29(6), 425-437.

de Jesus, A., \& Mendonca, S. (2018). Lost in transition? drivers and barriers in the eco-innovation road to the circular economy. Ecological Economics, 145(March 2018), 75-89.

Dereli, T., \& Altun, K. (2013). Technology evaluation through the use of interval type-2 fuzzy sets and. systems. Computers \& Industrial Engineering, 65(4), 624-633.

Deveci, M., Cetin-Demirel, N., \& Ahmetoglu, E. (2017). Airline new route selection based on interval type2 fuzzy MCDM: a case study of new route between Turkey-North American region destinations. Journal of Air Transport Management, 59, 83-99.

Ezzat, A.M. (2016). Sustainable development of seaport cities through circular economy: a comparative study with implications to Suez canal corridor project. European Journal of Sustainable Development, 5(4), 509-522.

Farooque, M., Zhang, A., \& Liu, Y. (2019). Barriers to circular food supply chains in China. Supply Chain Management: An International Journal, 24(5), 677-696.

Galvao, G.D.A., Nadae, J., Clemente, D.H., Chinen, G., \& Carvalho, M.M. (2018, May). Circular economy: overview of barriers. In 10th CIRP Conference on Industrial Product-Service Systems, 73, (pp.79-85). Linköping, Sweden.

Geisendorf, S., \& Pietrulla, F. (2018). The circular economy and circular economic concepts-a literature analysis and redefinition. Thunderbird International Business Review, 60(5), 771-782.

Geissdoerfer, M., Savaget, P., Bocken, N.M.P., \& Hultink, E.J. (2017). The circular economy - a new sustainability paradigm?. Journal of Cleaner Production, 143, 757-768. 
International Journal of Mathematical, Engineering and Management Sciences

Vol. 6, No. 3, 824-846, 2021

https://doi.org/10.33889/IJMEMS.2021.6.3.049

Girard, L.F., \& Nocca, F. (2017). From linear to circular tourism. AESTIMUM, 70, 51-74.

Govindan, K., \& Hasanagic, M. (2018). A systematic review on drivers, barriers, and practices towards circular economy: a supply chain perspective. International Journal of Production Research, 56(1-2), 278-311.

Govindan, K., Kaliyan, M., Kannan, D., \& Haq, A.N. (2014). Barriers analysis for green supply chain management implementation in Indian industries using analytic hierarchy process. International Journal of Production Economics, 147, 555-568.

Goyal, S., Esposito, M., \& Kapoor, A. (2018). Circular economy business models in developing economies: lessons from India on reduce, recycle, and reuse paradigms. Thunderbird International Business Review, 60(5), 729-740.

Gue, I.H.V., Promentilla, M.A.B., Tan, R.R., \& Ubando, A.T. (2020). Sector perception of circular economy driver interrelationships. Journal of Cleaner Production, 276, 123204.

Jiang, Y., \& Zhou, L. (2012, September). Study on green supply chain management based on circular economy. In International Conference on Solid State Devices and Materials Science, 25, (pp. 16821688). Macao, China.

John, R., \& Coupland, S. (2009). Type-2 fuzzy logic and the modelling of uncertainty in applications. In: Bargiela, A., \& Pedrycz, W. (eds), Human-Centric Information Processing Through Granular Modelling, pp.185-201. Springer, Berlin, Heidelberg.

Kahraman, C., Oztaysi, B., Ucal Sari, I., \& Turanoglu, E. (2014). Fuzzy analytic hierarchy process with interval type-2 fuzzy sets. Knowledge-Based Systems, 59, 48-57.

Kazancoglu, I., Kazancoglu, Y., Kahraman, A., Yarımoglu, E., \& Soni, G. (2020). Investigating barriers to circular supply chain in the textile industry from stakeholders' perspective. International Journal of Logistics Research and Applications, DOI: 10.1080/13675567.2020.1846694.

Kirchherr, J., Piscicelli, L., Bour, R., Kostense-Smit, E., Muller, J., Huibrechtse-Truijens, A., \& Hekkert, M. (2018). Barriers to the circular economy: evidence from the European Union (EU). Ecological Economics, 150, 264-272.

Kirchherr, J., Reike, D., \& Hekkert, M. (2017). Conceptualizing the circular economy: an analysis of 114 definitions. Resources, Conservation and Recycling, 127 (December 2017), 221-232.

Korhonen, J., Honkasalo, A., \& Seppala, J. (2018). Circular economy: the concept and its limitations. Ecological Economics, 143, 37-46.

Lebre, E., Corder, G., \& Golev, A. (2017). The role of the mining industry in a circular economy: a framework for resource management at the mine site level. Journal of Industrial Ecology, 21(3), 662-672.

Lee, L.W., \& Chen, S.M. (2008, July). A new method for fuzzy multiple attributes group decision-making based on the arithmetic operations of interval type-2 fuzzy sets. In 2008 International Conference on Machine Learning and Cybernetics, 6, (pp. 3084-3089). Kunming, China.

Lieder, M., \& Rashid, A. (2016). Towards circular economy implementation: a comprehensive review in context of manufacturing industry. Journal of Cleaner Production, 115(March 2016), 36-51.

Lindgreen, A., \& Swaen, V. (2010). Corporate social responsibility. International Journal of Management Reviews, 12(1), 1-7.

Manniche, J., Tops $\varnothing$ Larsen, K., Brandt Broegaard, R., \& Holland, E. (2017). Destination: A circular tourism economy: A handbook for transitioning toward a circular economy within the tourism and hospitality sectors in the South Baltic Region. 
International Journal of Mathematical, Engineering and Management Sciences

Vol. 6, No. 3, 824-846, 2021

https://doi.org/10.33889/IJMEMS.2021.6.3.049

233

234

235

236

237

238

239

240

241

242

243

244

245

246

247

248

249

250

251

252

253

254

255

256

257

258

259

260

261

262

263

264

265

266

267

268

269

270

271

272

273

274

Masi, D., Kumar, V., Garza-Reyes, J.A., \& Godsell, J. (2018). Towards a more circular economy: exploring the awareness, practices, and barriers from a focal firm perspective. Production Planning \& Control, 29(6), 539-550.

Moreau, V., Sahakian, M., Griethuysen, P.V., \& Vuille, F. (2017). Coming full circle: why social and institutional dimensions matter for the circular economy. Journal of Industrial Ecology, 21(3), 497-506.

Morseletto, P. (2020). Restorative and regenerative: exploring the concepts in the circular economy. Journal of Industrial Ecology, 24(4), 763-773.

Pamfilie, R., Firoiu, D., Croitoru, A.G., \& Ionescu, G.H. (2018). Circular economy - a new direction for the sustainability of the hotel industry in Romania?. Amfiteatru Economic, 20(48), 388-404.

Pan, S.Y., Gao, M., Kim, H., Shah, K.J., Pei, S.L., \& Chiang, P.C. (2018). Advances and challenges in sustainable tourism toward a green economy. Science of the Total Environment, 635, 452-469.

Prieto-Sandoval, V., Jaca, C., \& Ormazabal, M. (2018). Towards a consensus on the circular economy. Journal of Cleaner Production, 179, 605-615.

Ritzén, S., \& Sandström, G.Ö. (2017). Barriers to the Circular Economy-Integration of perspectives and domains. Procedia CIRP, 64, 7-12. DOI:10.1016/j.procir.2017.03.005.

Rizos, V., Behrens, A., Van der Gaast, W., Hofman, E., Ioannou, A., Kafyeke, T., Flamos, A., Rinaldi, R., Papadelis, S., Garbers, M.H., Topi, C. (2016). Implementation of circular economy business models by small and medium-sized enterprises (SMEs): barriers and enablers. Sustainability, 8(11), 1212.

Rodriguez, C., Florido, C., \& Jacob, M. (2020). Circular economy contributions to the tourism sector: a critical literature review. Sustainability, 12(11), 4338.

Saaty, T.L., \& Vargas, L.G. (2012). The seven pillars of the analytic hierarchy process. In: Models, Methods, Concepts \& Applications of the Analytic Hierarchy Process. International Series in Operations Research \& Management Science, vol 175, 23-40. Springer, Boston, MA. DOI:10.1007/978-1-4614-3597-6_2.

Schoggl, J.P., Stumpf, L., \& Baumgartner, R.J. (2020). The narrative of sustainability and circular economy - a longitudinal review of two decades of research. Resources, Conservation \& Recycling, 163, 105073.

Smol, M., Adam, C., \& Preisner, M. (2020). Circular economy model framework in the european water and wastewater sector. Journal of Material Cycles and Waste Management, 22, 682-697.

Sorensen, F., \& Baerenholdt, J.O. (2020). Tourist practices in the circular economy. Annals of Tourism Research, 85, 103027.

The Ellen MacArthur Foundation. (2013). Towards a Circular Economy - Economic and Business Rationale for an Accelerated Transition. Cowes, UK: Ellen MacArthur Foundation.

Vargas-Sanchez, A. (2018). The unavoidable disruption of the circular economy in tourism. Worldwide Hospitality and Tourism Themes, 10(6), 652-661.

Wu, H.Q., Shi, Y., Xia, Q., \& Zhu, W.D. (2014). Effectiveness of the policy of circular economy in china: a DEA-based analysis for the period of 11th five-year-plan. Resources, Conservation and Recycling, 83(February 2014), 163-175.

Yadav, G., Luthra, S., Jakhar, S.K., Mangla, S.K., \& Rai, D.P. (2020). A framework to overcome sustainable supply chain challenges through solution measures of industry 4.0 and circular economy: an automotive case. Journal of Cleaner Production, 254(2020), 120112

Zadeh, L.A. (1975). The concept of a linguistic variable and its application to approximate reasoning-I. Information Sciences, 8(3), 199-249. 
International Journal of Mathematical, Engineering and Management Sciences

Vol. 6, No. 3, 824-846, 2021

https://doi.org/10.33889/IJMEMS.2021.6.3.049

275 Zadeh, L.A. (1965). Fuzzy sets. Information and Control, 8(3), 338-353.

276 Zink, T., \& Geyer, R. (2017). Circular economy rebound. Journal of Industrial Ecology, 21(3), 593-602.

277 